\title{
EPIDEMIOLOGY OF RISK FACTORS OF VARIOUS MORPHOLOGICAL TYPES OF AGE-RELATED CATARACT IN EASTERN REGION OF NEPAL.
}

\author{
Namrata Gupta ${ }^{1 *}$, Poonam Lavaju', Sangeeta Shah ${ }^{3}$, Badri Prasad Badhu ${ }^{4}$
}

\begin{abstract}
Affiliation
1. Consultant Ophthalmologist, Paediatric Ophthalmology and Strabismus Specialist, Matrika Eye Center, Nepal

2. Professor, Department of Ophthalmology, B.P. Koirala institute of health sciences, Nepal

3. Associate Professor, Department of Ophthalmology, B.P. Koirala institute of health sciences, Nepal

4. Professor, Department of Ophthalmology, Birat Medical college, Nepal
\end{abstract}

\section{ARTICLE INFO}

Received : 23 March, 2021

Accepted : 11 August, 2021

Published : 04 November, 2021

(C) Authors retain copyright and grant the journal right of first publication with the work simultaneously licensed under Creative Commons Attribution License CC - BY 4.0 that allows others to share the work with an acknowledgment of the work's authorship and initial publication in this journal.

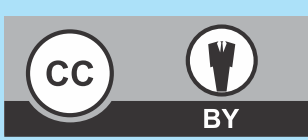

ORA 252

DOI: https://doi.org/10.3126/bjhs.v6i2.40320

\author{
* Corresponding Author \\ Dr Namrata Gupta \\ Consultant Ophthalmologist \\ Paediatric Ophthalmology and Strabismus Specialist \\ Matrika Eye Center, Nepal \\ Email:namratadoc@gmail.com \\ ORCID: https://orcid.org/0000-0002-9479-9612
}

\section{Citation}

Namrata Gupta, Poonam Lavaju, Sangeeta Shah, Badri Prasad Badhu. Epidemiology of risk factors of various morphological types of agerelated cataract in eastern region of Nepal. BJHS 2021;6(2)15. 1466-1470.

\section{ABSTRACT}

\section{Introduction}

Age related cataract is the leading cause of preventable blindness globally, with multi factorial risk factors. Multiple mechanism contributes to the progressive loss of lens transparency.

\section{Objective}

The purpose of this study is to determine the risk factors for different morphological types of senile cataract in eastern region of Nepal.

\section{Methodology}

A hospital based cross sectional study was conducted in a tertiary care hospital. Four hundred patients aged $\geq 50$ years with senile cataract attending eye out patient department for one year were enrolled and divided into two groups based on Lens Opacities Classification System (LOCS) III grading. Group A consisted of 'no-moderate' cataract and group B consisted of 'severe' cataract. The parameters studied were age, gender, education, occupation, smoking, alcohol consumption, diabetes and hypertension, body mass index and use of topical or oral medication. Statistical analysis was conducted to find an association of various parameters to different morphological type of cataract.

\section{Results}

The mean age of presentation was $61 \pm 9.07$ years. Male to female ratio was 1:02. Group A had 154 and group B 246 patients respectively. Statistically significant association was seen between older age group and severe cataract ( $p$ $<0.002$ ). Household activities and moderate alcohol consumption alcohol was seen associated with moderate nuclear sclerosis $(p<0.001)$ and posterior sub-capsular cataract $(p<0.003)$ respectively. High blood pressure was associated with severe Nuclear Sclerosis and Posterior Subcapsular Cataract $(p<0.014)$.

\section{Conclusion}

Older age groups, household activities, moderate alcohol consumption and high blood pressure were found to have significant association with age-related cataract.

\section{KEYWORDS}

Age-related cataract, LOCS III, Nuclear sclerosis, Posterior sub-capsular cataract, cortical cataract. 


\section{INTRODUCTION}

Age related cataract is the leading cause of blindness in the world today. With an estimated 10.8 million people blind and 35.1 million visually impaired due to cataract, it represents almost $33.4 \%$ of all causes of blindness due to eye diseases globally in 2010. ${ }^{1}$ In Nepal alone, the current prevalence of cataract is 87,500 and every year about 60,000 people get cataract. Although cataract prevalence is higher among women, cataract surgical coverage rate is 1.21.7 times lower for them. ${ }^{2}$

Epidemiological studies have established certain risk factors for cataract formation like age, female gender, genetics and modifiable risk factors like chronic UV exposure, smoking, alcohol consumption, diabetes, hypertension, low socioeconomic status, certain occupations. ${ }^{3}$

However, there are no published data regarding the distribution of these risk factors among the target population in Nepal. This study was carried out to identify the demographic pattern and prevalence of various risk factors for morphological types of cataract in our defined population. This study may help carry out research on the pathogenesis of lens opacity formation to prevent or reduce its progression. More importantly, it can aid the current public health efforts to take care of modifiable risk factors.

\section{METHODOLOGY}

A hospital based cross -sectional study was conducted in the out patient department of ophthalmology of BP Koirala Institute of Health Sciences in eastern Nepal for a duration of one year. The study population was enrolled using convenient and quota sampling method. For sample size calculation, a pilot study was conducted among patients presenting with senile cataract for one week to find out the prevalence of various morphological types of cataract. A total of 400 eyes of 400 patients with age related cataract aged $\geq 50$ years were included in the study. The study was approved by the Institutional ethical review board of B. P. Koirala Institute of Health Sciences (Code no: IERB/198/014) and in accordance of declaration of Helsinki.

Patients with lens opacification due to trauma, previous history of intra ocular inflammation, complicated cataract and history of intra ocular surgery in the same eye were excluded from the study.

After obtaining informed consent, pupil was dilated with tropicamide $1 \%$ and morphology of the lens was examined under the slit lamp biomicroscope. The Lens Opacities Classification System III (LOCS) was used for grading lens. Lens was classified into four major groups based on slit lamp images. Six images were used for grading Nuclear color (NC) and nuclear opacity (NO) from 0-6.9, five retro-illumination images for grading cortical cataract ( C) from 0-5.9, and five retro-illumination images for grading posterior subcapsular (P) cataract from 0-5.9. ${ }^{4}$ Based on severity cataract was divided into three grades as shown in Table 1.
Table 1: Cataract grades based on severity

\begin{tabular}{|l|l|}
\hline Grade of cataract & LOCS III score \\
\hline Severe cataract & $\geq 4$ for $\mathrm{NO}$ or $\geq$ for $\mathrm{NC}$ \\
& $\geq 4$ for $\mathrm{C}$ \\
& $\geq 2$ for $\mathrm{P}$ \\
\hline Moderate cataract & $2 \leq \mathrm{NO} \geq 4$ or $2 \leq \mathrm{NC} \geq 4$ \\
& $2 \leq \mathrm{C} \geq 4$ \\
& $1 \leq \mathrm{P}<2$ \\
\hline No Cataract & $\mathrm{NO}<2$ and $\mathrm{NC}<2, \mathrm{C}<2$ and $\mathrm{P}<1$ \\
& no cataract \\
\hline
\end{tabular}

The patient with all three types of cataract was categorized under mixed cataract. If the patient had bilateral cataract, the eye with severe grade of cataract was taken in the study. For our convenience, the three grades of cataract were further divided into two groups. Group A consisted of 'Nomoderate cataract' with LOCS score $\leq 4$ for Nuclear cataract (NS) and cortical cataract and $<2$ for Posterior Subcapsular cataract (PSC). Group B consisted of 'Severe cataract' with LOCS score $>4$ for NS and cortical and $\geq 2$ for PSC.

Socio-demographic risk factors included age, gender, occupation and education. Education was categorized into four groups based on highest education level: No formal education, primary (grade 6 or less), secondary (grade 7-10), tertiary $\left(11^{\text {th }}\right.$ grade or higher, including university education). ${ }^{5}$

The biological risk factors included current history of smoking, self-reported history of diabetes mellitus and hypertension, family history of lens opacities, use of drugs, frequency and amount of alcohol consumption, BMI, blood pressure and blood glucose level.

Smoking history was determined by whether the patients were current smokers or past smokers or non-smokers. Current smokers were defined as individuals who were currently smoking or had stopped smoking less than 1 year before examination. Number of pack years was calculated as number of cigarettes smoked per day $\mathrm{x}$ number of years smoked/20 (1 pack has 20 cigarettes). ${ }^{6}$

The participants were asked about all the medications (prescription and over-the- counter) that they were regularly taking. History of intake of drugs that increase the risk of cortical cataract such as oral steroids, oral hypoglycemic agents, insulin, $\beta$-blockers, NSAIDS was recorded.

Frequency of alcohol consumption as daily, weekly, monthly, or less often was recorded. For easier interpretation, the total alcohol intake was recorded into number of drinks, assuming 1 drink contained 13 grams of alcohol, corresponding to $330 \mathrm{ml}$ of beer, $150 \mathrm{ml}$ of wine, or $45 \mathrm{ml}$ of liquor. ${ }^{7}$

Body mass index was graded into four grades: Underweight (<18.5), Normal (18.5-24.9), Overweight (25-29.9) and Obese (>30)

Diabetes mellitus was defined as a RBS of $200 \mathrm{mg} / \mathrm{dl}$, or higher or use of diabetic medication or self-report of physician diagnosis. In our study random blood sugar was labeled as controlled (80-140 mg) and uncontrolled (>140 mg) The blood pressure of patients was recorded at the time of 
examination in right and left arm using sphygmomanometer. Grading of blood pressure was done according to $\mathrm{WHO} / \mathrm{ISH}$ into 4 grades: normal (<140/90), grade 1 (140-159/90-99), grade 2 (160-179/100-109) grade $3(\geq 180 / 110){ }^{8}$

All the data collected were entered into SPSS version 11 . For inferential statistics parametric and nonparametric tests were carried out at $95 \%$ confidence interval where $p$ value $\leq 0.05$.

\section{RESULTS}

Of the 400 eyes of 400 patients examined, the mean age of presentation was $61.96 \pm 9.07$ years. The male to female ratio was 1.02:1. Most of the patients were uneducated (63.7\%) and mainly involved in household activities (39.7\%). Among the patients. $63.3 \%$ were non-smokers and $70 \%$ did not consume alcohol. Most of the patients were non diabetic (81.5\%) and non-hypertensive (77.5\%). Among the patients, $61.5 \%$ had severe cataract and $38.5 \%$ had 'nomoderate' cataract. Distribution of morphological types of cataract among the two groups is depicted in figure 1.

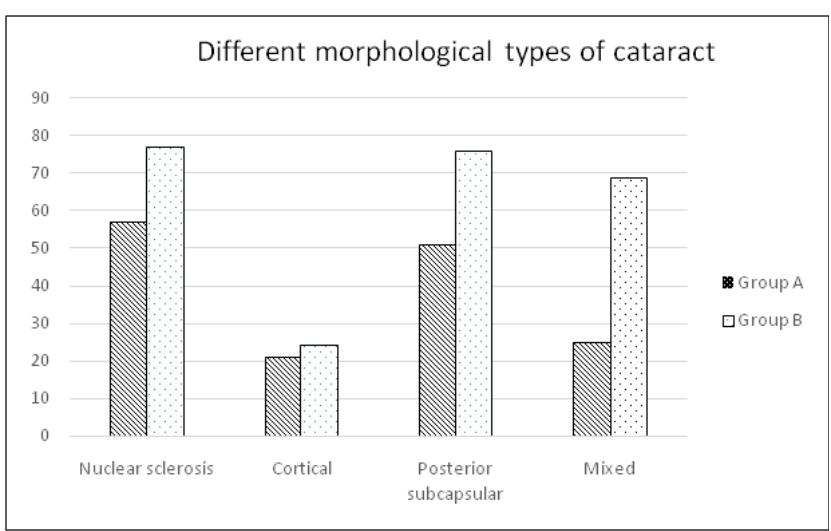

Figure 1: Distribution of different morphological types of cataract among two groups.

Most of the study patients were in the age group of 50-60 years among which Group A had $53.2 \%$ patients and group B, $57.3 \%$. Figure 2 shows the distribution of different types of cataract in the two groups among different age group. (Figure 2)

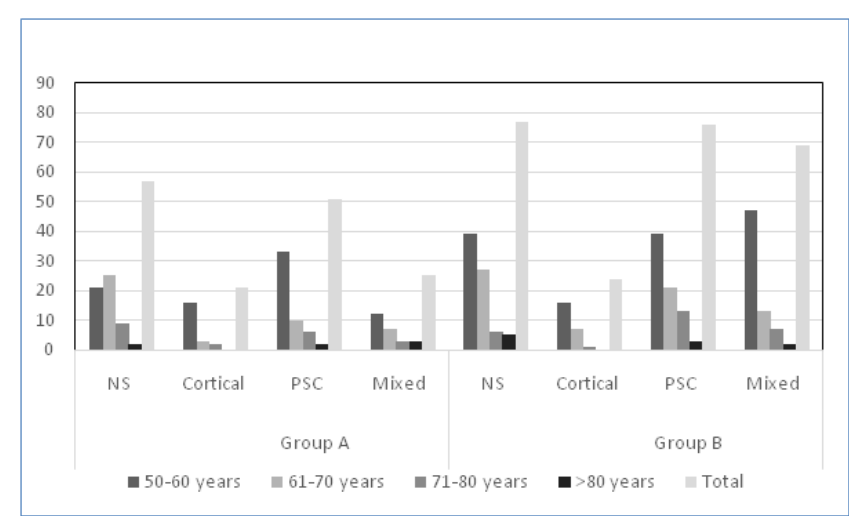

Figure 2: Distribution of different types of cataract among different age group in Group A and Group B

Significant association was seen betweenolder age group andsevere form of nuclear sclerosis in group $B$ ( $p$ $<0.029)$. There was no significant association between increasing age and prevalence of moderate cataract in group $A(p<0.161)$

Severe form of senile cataract was more prevalent $(61.5 \%)$ in both genders. Male predominantly had severe form of NS (32.3\%) and cortical (32.3\%) cataract whereas females had severe form of mixed cataract (31\%). There was no significant association of gender with prevalence of different morphological forms of cataract, with $p<0.092$ and $p<0.806$ in group $A$ and group $B$ respectively.

Most of the patients in group A were uneducated (66.2\%) among which $44.1 \%$ had NS, $21.7 \%$ had PSC, $16.7 \%$ had mixed form and $11.8 \%$ had cortical cataract. In group B, $62.2 \%$ were uneducated among which $29.4 \%$ had nuclear sclerosis, $31.4 \%$ had PSC, $9.8 \%$ had cortical cataract and $29.4 \%$ had mixed type of cataract. There was no significant association seen between state of literacy and morphological form of cataract with $p$ value $<0.072$ for group $A$ and $<0.968$ for group $A$ and group B respectively.

Among the 400 patients, 159 (39.7\%) were engaged in house hold activities, 102 (25.5\%) were farmers, 74 (18.5\%) were engaged in some sort of business and 65 (16.2\%) had other occupation including army, journalism, clerkship, or mechanics.

Household activity was seen significantly associated with the prevalence of moderate grade of age-related cataract (NS), $p<0.001$ (figure 3 ).

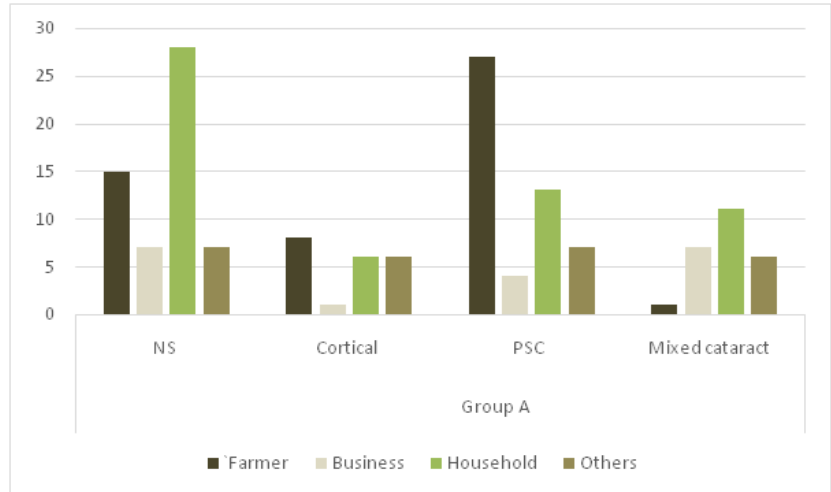

Figure 3: Distribution of different types of cataract among different occupations in group A.

There was no significant association between occupation and occurrence of severe cataract in group $B, p>0.659$.

Most of the patients in the study were found to be nonconsumers of alcohol (70\%). There was no significant association found between prevalence of moderate cataract and alcohol consumption, $p>0.334$. However, among group B patients, $32.9 \%$ consumed of alcohol with an average consumption of 2 glass (approx. $600 \mathrm{ml}$ ) /day. There was significant association between alcohol consumption and occurrence of PSC in group B with $p<0.003$ (figure 4).An association between blood pressure, blood sugar and BMI among different types of age- related cataract in two groups is illustrated in the table 2. High blood pressure was not found significantlyassociated with moderate age-related cataract $(p<0.062)$. However, Grade III hypertension $\geq 180 / 110$ 
$\mathrm{mm}$ of $\mathrm{Hg}$ was seen significantly associated with severe form of cataract with equal incidence of both NS and PSC $(p<$ 0.014). Among 400 patients, only 84 patients had RBS level above $140 \mathrm{mg} / \mathrm{dl}$. There was no significant association between RBS level and occurrence of moderate age-related cataract ( $p$-value $<0.246$ ) as well as severe age-related cataract ( $p$-value $<0.284$ )

Among the patients, $90.3 \%$ patients had BMI withing the normal range with no significant association seen with prevalence of moderate and severe age-related cataract. $(p<0.356$ and $p<0.441$ respectively)

Table 2: Association between blood pressure, blood sugar and BMI among different types of age- related cataract in two groups.

\begin{tabular}{|l|c|c|c|c|c|c|c|c|c|c|}
\hline \multirow{2}{*}{ Variable } & \multicolumn{9}{|c|}{ Group A } & \multicolumn{5}{c|}{ Group B } \\
\cline { 2 - 12 } & NS & Cortical & PSC & Mixed & p-value & NS & Cortical & PSC & Mixed & P-value \\
\hline $\begin{array}{l}\text { High BP } \\
\text { Grade III } \\
\text { hypertension }\end{array}$ & 16 & 4 & 11 & 9 & 0.062 & 22 & 6 & 22 & 7 & 0.014 \\
\hline High RBS & 7 & 6 & 19 & 7 & 0.246 & 12 & 8 & 18 & 15 & 0.284 \\
\hline High BMI & 3 & 0 & 4 & 4 & 0.356 & 10 & 4 & 12 & 8 & 0.441 \\
\hline
\end{tabular}

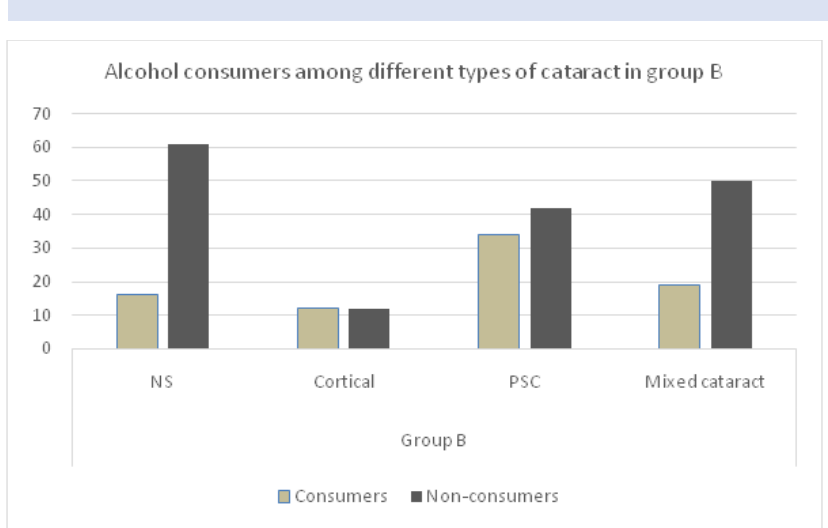

Figure 4: Distribution of alcohol consumers among different types of cataract in group $B$

\section{DISCUSSION}

This was a hospital based cross sectional study carried out to determine the underlying risk factors for different morphological types of age-related cataract.

The risk factors were studied based on previous studies in different parts of the world and its prevalence was determined in our study group. Our target population mainly consisted of Nepalese population of eastern belt as well as from northeastern part of India across the borders with similar geographical and living conditions.

Among the significant characteristics, increasing age was found to be significantly associated with moderate grade of PSC and mixed type of cataract. The findings were consistent with previous studies. ${ }^{9}$

The prevalence being less in the age group of 80 years and above $(4.2 \%)$ as compared to $50-60$ years $(53.2 \%)$ could be explained by increased awareness and early presentation of people with age-related cataract due to visual disability and need for early intervention.

In our study, age related cataract was seen slightly more in males $(50.5 \%)$ than females $(49.5 \%)$. It was not consistent with the findings of previous studies. ${ }^{3}$ This possibly may be due to less exposure of females to potential risk factors or due to social barriers for early presentation among females in this part of the world as compared to males.

Most of the patients in our study were engaged in household activities among which moderate NS was more prevalent. Significant association was found between household activities and prevalence of moderate grade of NS ( $p<0.001)$. Leske et ${ }^{10}$ all described increased association of non-professional occupation and low socio-economic status with increased incidence of nuclear and cortical opacities.

The prevalence of age-related cataract in this study population was irrespective of current or past smoking history inconsistent with the findings in previous studies. ${ }^{11}$ The additive role of other putative risk factors could possibly be the cause.

However, age related cataract has significant association with moderate consumption of alcohol $(p<0.003)$.Lindblad et $\mathrm{al}^{7}$ in their study noted that daily intake of $\geq 1$ alcoholic drink was associated with a modest increase of risk for cataract extraction. The risk increased with increasing alcohol consumption.

In this study the level of blood sugar was not seen to be significantly associated risk factor, possibly due to smaller sample size. Unlike our study in a study done byTan et all ${ }^{12}$ showed significantly increased risk of high blood sugar level with incident cortical cataract.

In the present study, high blood pressure was found to be significantly associated with increased incidence of severe NS and PSC. It was seen consistent with a study by Christine $Y$ et $\mathrm{al}^{13}$ in which statistically significant association was seen with high blood pressure and posterior subcapsular cataract.

Age-related cataract is a major cause of blindness through out the world which needs better understanding of its etiopathogenesis and prevention. The study was primarily interview based and grading of lens based on photographic standards which can lead to observers bias during elaboration of risk factors and grading of severity of cataract.

\section{CONCLUSION}

Older age, household occupation, alcohol consumption and high blood pressure were identified as risk factors for the development of different morphological types of agerelated cataract. This study creates room for a larger study with prospective analysis of risk factors and its association with age-related cataract that can help reduce the burden of avoidable blindness in our country.

\section{RECOMMENDATIONS}

Age-related cataract is a major cause of blindness throughout the world which needs better understanding of its etio-pathogenesis and prevention. The higher prevalence of environmental and socio-economic risk 
factors in developing countries like ours, that pose a risk of early development of severe Age-related cataract needs special attention. Efforts towards prevention and better understanding of putative risk factors may help reduce the burden of visual disability due to age-related cataract.

\section{LIMITATIONS OF THE STUDY}

The sample size was small as compared to previous studies. Due to variable presentation of patients from different regional areas, the sample was not a true representation of eastern Nepal. The study was primarily interview based and grading of lens based on photographic standards which can lead to observers bias during elaboration of risk factors and grading of severity of cataract.

\section{ACKNOWLEDGEMENT}

I take this opportunity to extend my gratitude to Mr. D. D. Baral and Dr Surya Niraula for their expert opinion and helping me in statistical analysis.

I would also like to thank all the staff of the department of Ophthalmology for their valuable help.

And finally, I whole-heartedly acknowledge all the patients and their care takers without whose co-operation this study would not have been successful.

\section{CONFLICT OF INTEREST}

None

\section{SOURCES OF SUPPORT None}

\section{REFERENCES}

1. Khairallah M, Kahloun R, Bourne R, Limburg H, Flaxman SR, Jonas JB, et al. Number of People Blind or Visually Impaired by Cataract Worldwide and in World Regions, 1990 to 2010. 2015;

2. Sapkota YD, Limburg H. Epidemiology of Blindness in Nepal: 2012. 1st ed. Kathmandu: Nepal Netra Jyoti Sangh; 2012.

3. Robman L, Taylor H, L Robman HT. External factors in the cevelopment of cataract. Eye. 2005 Oct;19(10):1074-82.

4. Chylack LT, Wolfe JK, Singer DM, Leske MC, Bullimore MA, Bailey IL, et al. The Lens Opacities Classification System III. The Longitudinal Study of Cataract Study Group. Arch Ophthalmol. 1993;111 (6):831-6.

5. Foster PJ, Wong TY, Machin D, Johnson GJ, Seah SKL. Risk factors for nuclear, cortical and posterior subcapsular cataracts in the Chinese population of Singapore: the Tanjong Pagar Survey. $\mathrm{Br} \mathrm{J}$ Ophthalmol. 2003;87(9):1112-20.

6. Tan JSL, Wang JJ, Younan C, Cumming RG, Rochtchina E, Mitchell P. Smoking and the long-term incidence of cataract: the Blue Mountains Eye Study. Ophthalmic Epidemiol. 15(3):155-61.

7. Lindblad BE, Håkansson N, Philipson B, Wolk A. Alcohol consumption and risk of cataract extraction: a prospective cohort study of women. Ophthalmology. 2007;114(4):680-5.
8. Brookes Linda. The updated WHO/ISH Hypertension guidelines. medscape cardiology. 2004.

9. Delcourt C, Cristol JP, Tessier F, Léger CL, Michel F, Papoz L. Risk factors for cortical, nuclear, and posterior subcapsular cataracts: the POLA study. Pathologies Oculaires Liées à l'Age. Am J Epidemiol. 2000;151(5): 497-504.

10. Leske MC, Wu SY, Connell AM, Hyman L, Schachat AP. Lens opacities, demographic factors and nutritional supplements in the Barbados Eye Study. Int J Epidemiol. 1997;26(6):1314-22.

11. Wu R, Wang JJ, Mitchell P, Lamoureux EL, Zheng Y, Rochtchina E, et al. Smoking, socioeconomic factors, and age-related cataract: The Singapore Malay Eye study. Arch Ophthalmol. 2010;128(8):1029-35.

12. Tan JSL, Wang JJ, Mitchell P. Influence of diabetes and cardiovascular disease on the long-term incidence of cataract: the Blue Mountains eye study. Ophthalmic Epidemiol. 2008;15(5):317-27.

13. C Younan, P Mitchell R cumming, Younan C, Mitchell P, Cumming RG, Panchapakesan J, Rochtchina E, et al. Hormone replacement therapy, reproductive factors and the incidence of cataract and cataract surgery. The Blue Mountans Eye Study. Am J Epidemiol. 2002 Jun 1;155(11):997-1006. 